\title{
Analysis of Dynamic Inspection Respond of Integrity Float Supported Pile
}

\author{
Dongwei Wang \\ Xiamen University Tan Kah Kee College, Fujian, China
}

\begin{abstract}
In engineering construction, Piles have been come important base reinforce form. In this paper we established the mechanical model of the pile motivated vibration, and got the vibration partial differential equation of the pile, with the boundary conditions and initial conditions. From the mathematical calculation and derivation we concluded its time domain response by the method of separation of variables, and then through the fast Fourier transform, obtained its amplitude frequency response curves. An example was calculated to provide reference for the dynamic test study of the pile. The result we have got to serve as a guide for theory research of the pile.
\end{abstract}

Keywords-float supported pile; lengthwise oscillations; dynamic inspection

\section{INTRODUCTION}

In ports, offshore oil platforms, bridges, high-rise buildings, heavy plant, nuclear power plants and other projects, the use of large pile foundation reinforcement has become an important foundation form in the construction of our country. The pile can be used to spread its upper structure load to the deep layer, and it is proved to be an effective, safe and reliable foundation.But the pile in the construction process may appear rupture, bulging, shrinkage neck and segregation, so that the pile quality is affected, thus affecting the pile bearing capacity.

Pile bearing capacity test is an important issue in the field of geotechnical engineering, Dynamic Inspection of the pile is also an important means to ensure the quality of foundation engineering. Static load test can be used to effectively detect the pile bearing capacity, but it needs a long time, and is expensive, for the sampling rate being low and easy damage of pile foundation and in some cases it is difficult to test. With the needs of the engineering and technical progress, and increasing the use of large diameter and extra long pile, it increases the difficulty of the static load test of the pile bearing capacity. At present, the dynamic testing technology at home and abroad have been applied, but due to the dynamic pile testing technology both in theoretical basis, test analysis techniques and in engineering application have great difficulty, so the technology still exists a lot of problems, it is necessary to do further research and development. Low strain dynamic testing of pile bearing capacity method is by the test of pile-soil system dynamic response dynamic stiffness to infer ultimate pile load. The displacement of low strain dynamic testing at pile top is very small in the static load test curve against the dynamic stiffness of the equivalent distribution, according to the dynamic stiffness to predict the bearing capacity, or according to the linear equivalent static load test curve to infer the turning point of the static load test curve, may be very difficult.
Although the theoretical research shows that even if the nonlinear deforamation of material, the stress-strain curve can push and follow the law, but because of the complexity of the actual conditions, it is difficult to theoretically give a satisfactory answer, so the low strain dynamic test has not been accepted by the engineering department. Using the method of vibration and shock test, due to the large excitation energy, the pile displacement is obvious, and test information in different degrees including piles bearing capacity information, can be used for measuring and checking the quality of pile body. For the safety of the engineering structure, in construction we must ensure that the integrity of pile body and the pile bearing capacity. But due to the geological conditions and pouring concrete construction process to the pile being not uniform or discontinuous quality defects, we must have a pile quality test.

Dynamic testing method is an important method for the quality inspection of pile foundation. Compared with the static load test, this method is simple, rapid, inexpensive and so on, and its reliability has been proved in practice gradually.

The testing methods of the pile vibration were introduced by $\mathrm{Xu}$ You, Liu Xingman [1]. The theoretical study of elastic vibration was also carried out many years ago[2]. Some other methods were also described for pile vibration detection. So we could use the vibration theory to analyze the pile quality.

In this paper, we established the mechanical model of the pile motivated vibration, got the vibration partial differential equation of pile, with the boundary conditions and initial conditions, through the mathematical calculation and derivation we concluded its time domain response using the method of separation of variables, and then through the fast Fourier transform, obtained its amplitude frequency response curves. An example was calculated to provide reference for the dynamic test study of the pile.

\section{THE VIBRATION ANALYSIS OF THE FLOATING PILE}

In the paper, A pile - soil system must be considered to study the vibration of the pile.

To simplify the problem, it is assumed that (1) the pile soil testing is uniform, (2) pile soil interaction is equal to a spring and damper coupled in parallel coupling, (3) pile soil strain in the exciting force is small and can be considers within the linear elastic range, (4) frequency estimation error is ignored for an equivalent linear spring and damper model.

By dynamic testing method in detection of pile foundation, we often use to pile soil system equivalent system (the socalled dynamic stiffness and damping system) as an important 
prerequisite to evaluate the pile foundation quality. As shown in figure 1.
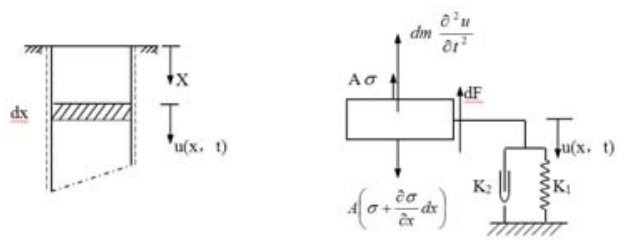

FIGURE I. COUPLING OF PILE-SOIL STRESS ANALYSIS

Reference figure (1), the analysis of the force of micro segment $\mathrm{dx}$ is shown as following:

$$
d F=k_{1} u d x+k_{2} \frac{\partial u}{\partial x} d x
$$

$\mathrm{K} 1$ - the equivalent spring coefficient of pile side soil

$\mathrm{K} 2$ - the equivalent damping coefficient of pile side soil

$\mathrm{U}(\mathrm{x}, \mathrm{t})$ - the displacement of the point $\mathrm{x}$ from the top at $\mathrm{t}$ moment

$\mathrm{dF}$ - the resistance of pile side soil to unit $\mathrm{dx}$

$$
A\left(\sigma+\frac{\partial \sigma}{\partial x} d x\right)-A \sigma-d F=A d x \frac{\partial^{2} u}{\partial t^{2}} \rho
$$

A - the pile cross section area

$\sigma$ - the cross section stress of the pile body

$\rho$ - the pile density

By:

$$
\sigma=E \frac{\partial u}{\partial x}
$$

E - Elastic modulus of the pile

By the above formula, after simplification:

$$
m \ddot{u}+k_{2} \dot{u}+k_{1} u-r u^{\prime \prime}=0
$$

In the formula:

$r$ - the axial stiffness of the pile, $r=E A$

$\mathrm{m}$ - The mass per unit length of the pile, $m=\rho A$

Using the method of separation of variables, the initial conditions and boundary conditions, We have drown the equation and got the result as follows:

Make:

$$
u(x, t)=X(x) T(t)
$$

According to the formula (2) could get:

$$
m X(x) \ddot{T}(t)+k_{2} X(x) \dot{T}(t)+k_{1} X(x) T(t)=r X^{\prime \prime}(x) T(t)
$$

$$
\frac{m \ddot{T}(t)+k_{2} \dot{T}(t)+k_{1} T(t)}{T(t)}=\frac{r X^{\prime \prime}(x)}{X(x)}=-R
$$

The $\mathrm{R}$ is a real number, and $\mathrm{R}>0$, therefore:

$$
\begin{aligned}
& r X^{\prime \prime}(x)+R X(x)=0 \\
& m \ddot{T}(t)+k_{2} \dot{T}(t)+\left(k_{1}+R\right) T(t)=0
\end{aligned}
$$

Make:

$$
T(t)=A e^{\alpha t}
$$

By the formula (4) could get:

$$
\begin{gathered}
m \alpha^{2}+k_{2} \alpha+k_{1}+R=0 \\
\alpha=-n_{i}+i \omega_{d i} \\
n_{i}=\frac{k_{2}}{2 m} \\
\omega_{d i}=\sqrt{p_{i}^{2}+\frac{k_{1}}{m}-\frac{k_{2}^{2}}{4 m^{2}}}
\end{gathered}
$$

pi-Natural frequency of the pile without soil, $\mathrm{pi}=\mathrm{R} / \mathrm{m}$

For the floating pile, elastic support at the lower end and the top end, the boundary conditions are:

$$
\begin{gathered}
\left.r \frac{\partial u(x, t)}{\partial x}\right|_{x=0}=-\left.k u(x, t)\right|_{x=0} \\
\left.\frac{\partial u(x, t)}{\partial x}\right|_{x=l}=0 \quad \mathrm{t}>0
\end{gathered}
$$

$\mathrm{K}$ - the pile subsoil equivalent stiffness.

Initial condition:

The initial displacement is zero.

$$
\left.u(x, t)\right|_{t=0}=0
$$

At the pile top end, $\mathrm{X}=\mathrm{L}$, there are an instantaneous impact force, so

$$
\left.\frac{\partial u(x, t)}{\partial x}\right|_{\substack{t=0 \\ x=L}}=v_{0}
$$

By the introduction of pulse function, there is

$$
\left.\frac{\partial u(x, t)}{\partial x}\right|_{t=0}=\frac{I \delta(l-x)}{\rho A}
$$


I expressed the impulse at first.

$$
\begin{gathered}
f_{1}(x)=0 \\
f_{2}(x)=\frac{I \delta(l-x)}{\rho A} \\
X_{i}=C_{i}\left(\cos \frac{p_{i}}{v_{c}} x+\frac{v_{c} k}{r p_{i}} \sin \frac{p_{i}}{v_{c}} x\right) \\
\Phi_{0 i}=\int_{0}^{l} f_{1}(x) X_{i} d x=0 \\
\dot{\Phi}_{0 i}=\int_{0}^{l} f_{2}(x) X_{i} d x=\int_{0}^{l} X_{i} \frac{I \delta(l-x)}{\rho A} d x=X_{i l} \frac{I}{\rho A}
\end{gathered}
$$

Therefore:

$$
u=\sum_{i=1}^{\infty} \frac{I}{\rho A} X_{i} X_{i l} \frac{1}{\omega_{d i}} e^{-n_{i} t} \sin \omega_{d i} t
$$

After mathematical deduction, the partial differential equations are solved. We obtained the following results:

$$
\begin{gathered}
u_{l}=\frac{2 I}{\rho A l} \sum_{i=1}^{\infty} \frac{\left[1+\left(\frac{v_{c} k}{r p_{i}}\right)^{2}\right]^{2}}{\left[1+\left(\frac{v_{c} k}{r p_{i}}\right)^{2}\right]^{2}+\frac{2 v_{c}^{2} k}{r l p_{i}^{2}}} \frac{1}{\omega_{d i}} e^{-n, t} \sin \omega_{d i} t \\
\operatorname{tg} \frac{l p_{i}}{v_{c}}=\frac{v_{c} k}{r p_{i}} \quad \mathrm{i}=1,2, \ldots \\
\omega_{d i}=\sqrt{p_{i}^{2}+\frac{k_{1}}{m}-\frac{k_{2}^{2}}{4 m^{2}}} \\
v_{c}=\sqrt{E / \rho}=\sqrt{r / m}
\end{gathered}
$$

\section{NUMERICAL EXAMPLE}

On the pile 13 meters long, cross-sectional area of $0.76 \mathrm{~m}^{2}$, $k_{1}=0.45 \mathrm{MN} / \mathrm{m}^{2}, \quad k_{2}=0.06 \mathrm{MN} \cdot \mathrm{S} / \mathrm{m}^{2}, \rho=2.6 \mathrm{~g} / \mathrm{cm}^{3}$, wave velocity of $3500 \mathrm{~m} / \mathrm{s}$, with mass $\mathrm{W} 0=300 \mathrm{~kg}$ down from 2 meters high to maul, we calculated the time domain response, transformed through FFT, and concluded the time domain response curve and the amplitude frequency response curve graph shown in figure 2 and 3.

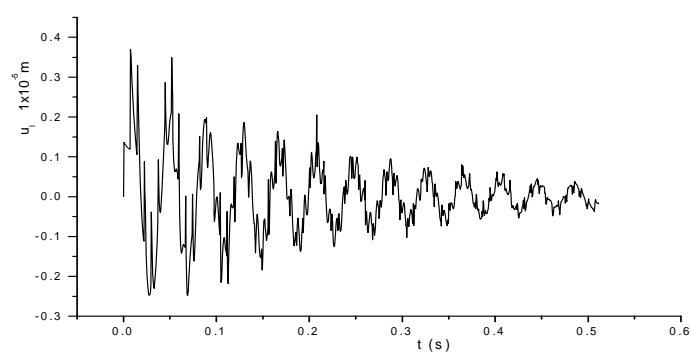

FIGURE II. THE TIME DOMAIN RESPONSE CURVE

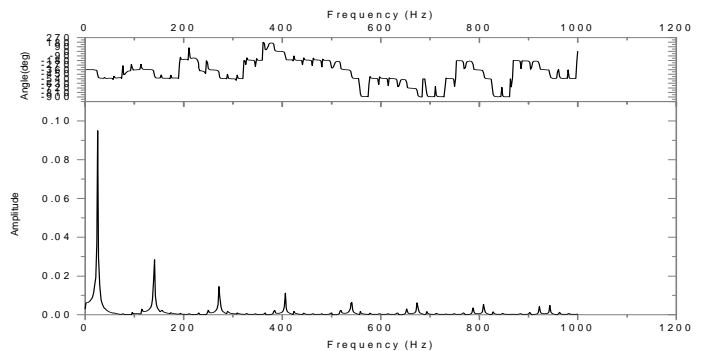

FIGURE III. THE AMPLITUDE FREQUENCY RESPONSE CURVE

We also got the maximum displacement amplitude of different damping coefficients as follows:

TABLE I. MAXIMUM DISPLACEMENT AMPLITUDE OF DIFFERENT DAMPING COEFFICIENTS

\begin{tabular}{cc}
\hline $\begin{array}{c}\text { damping coefficients } \\
\left(\mathrm{KNs} / \mathrm{m}^{2}\right)\end{array}$ & $\begin{array}{c}\text { Maximum displacement } \\
\text { amplitude }(\mathrm{mm})\end{array}$ \\
\hline 60 & 0.372 \\
160 & 0.130 \\
300 & 0.0936 \\
\hline
\end{tabular}

\section{CONCLUSION}

Through the above theoretical analysis and practical calculation it can be concluded that of amplitude-frequency curve peak of the full float pile at the first order Natural frequency is higher than others. If it appears higher peaks two or more, the pile body may have defects. With the increase of damping, the maximum displacement amplitude decreases, and the pile side soil has great influence on pile body vibration amplitude.

\section{REFERENCES}

[1] Xu You, Liu Xingman. New technique of dynamic measurement [M]. Chinese Architecture Industry Press, 1989.

[2] Yang Guitong, Zhang Shanyuan. Elastic dynamics [M]. China Railway Publishing House, 1988.

[3] Lei Linyuan. Dynamics of pile foundations[M]. Metallurgical Industry Press, 2000

[4] China Academy of building research. Technical code for building pile foundation [S]. China Building Industry Press, 2008.

[5] China Academy of building research. Code for design of concrete structures [S]. China Building Industry Press. 
[6] Huang Huang. Discussion and practical example of theoretical characteristic waveform of pile foundation nondestructive testing. West China exploration project, 2004 eleventh

[7] Jiang Wenguo. Transient Rayleigh wave extraction technology and its engineering application [J]. Highway traffic science and technology (technology). 2011 (12), pp. 133-134.

[8] Jian-wen cui, Johnson, FanYao new. Transient surface wave exploration technique in the application of engineering geology [J]. Journal of geotechnical engineering. 1996 (3), pp. 35-40.

[9] Li Zhesheng. Transient and whether the wave exploration technology application in the geotechnical engineering [J]. Journal of engineering survey. 1996 (3), pp. 66-68.

[10] Jun-long liu. With single pile ultimate bearing capacity standard penetration number estimation $[\mathrm{J}]$. Journal of geotechnical engineering. 2000 (02) pp. 88-91.

[11] Xian-min zhang. Transient surface wave testing technology and its application in civil engineering $[\mathrm{J}]$. Journal of hebei university of technology, 2000 (01), pp. 11-16.

[12] Liu Yunzhen zhen-dong wang. Transient surface wave method of data collection and processing system and its applications [J]. Journal of geophysical and geochemical exploration. 1996 (01), pp. 66-68. 